\title{
Os Portfólios como instrumento avaliativo em uma proposta de Ensino por Investigação
}

\section{The Portfolios as an evaluation tool in a Research Teaching proposal}

\author{
Mateus Lorenzon (mateusmlorenzon@ gmail.com) ${ }^{1}$ \\ Rede Pública de Ensino de Arroio do Meio - RS
}

\begin{abstract}
Resumo: Neste artigo, investiga-se as contribuições do portfólio como instrumento avaliativo em uma proposta de Ensino por Investigação. $\mathrm{O}$ estudo caracteriza-se como uma pesquisa-ação, desenvolvida junto a uma turma do $3 .^{\circ}$ ano do Ensino Fundamental. O corpus da pesquisa é constituído por Portfólios Individuais dos estudantes e pelo Diário de Aula mantido pelo docente, sendo estes analisados por meio da Análise Textual Discursiva. Os dados foram dispostos em três categorias, sendo que a primeira trata das possibilidades desse instrumento servir como um recurso que dê visibilidade às aprendizagens das crianças. A segunda categoria aborda a possibilidade dos portfólios fomentarem a comunicação entre as crianças e os docentes, evidenciando os interesses e as necessidades. A terceira categoria trata do desenvolvimento da metacognição, visto que ao elaborarem seus portfólios as crianças têm a oportunidade de refletirem sobre as tarefas que realizam e criarem estratégias para aperfeiçoá-las. Assim, evidencia-se que o uso de portfólios como um instrumento de avaliação permite ao docente acompanhar e monitorar o desenvolvimento da aprendizagem dos estudantes e planejar estratégias de trabalho adequadas às dificuldades apresentadas pelas crianças.
\end{abstract}

Palavras-chave: Avaliação. Documentação Pedagógica. Portfólio. Metacognição.

Abstract: In this article, we investigate the contributions of the use of portfolios as an evaluation tool in a inquiry teaching proposal. The study is characterized as an action research, developed with a class of the 3rd year of Elementary School. The corpus of the research is made up of Individual Portfolios of the students and the Classroom Journal maintained by the teacher, and these are analyzed through the Discursive Textual Analysis. The data were arranged in three categories, and the first deals with the possibilities of this instrument to serve as a resource that gives visibility to the children's learning. The second category addresses the possibility of portfolios fostering communication between children and teachers, highlighting interests and needs. The third category deals with the development of metacognition, since in developing their portfolios, children have the opportunity to reflect on the tasks they perform and to create strategies to improve them. Thus, it is evident that the use of portfolios as an evaluation tool allows the teacher to monitor and monitor the development of student learning and to plan work strategies that are adequate to the difficulties presented by the children.

${ }^{1}$ Discente do Programa de Pós Graduação em Ensino - UNIVATES. Graduado em Pedagogia UNIVATES. Docente na rede pública de ensino de Arroio do Meio/RS. 
Keyword: Evaluation. Pedagogical Documentation. Portfolio. Metacognition.

\section{INTRODUÇÃO}

O entendimento de que a participação em investigações favorece a aprendizagem dos estudantes apareceu nos discursos educacionais no final do século XIX. Nesse período, cientistas de renome, tais como Thomas Huxley, Herbert Spencer e Jonhann Friedrich Herbart, empreenderam esforços significativos para incluir o estudo de ciências nos currículos escolares que, até então, eram predominantemente voltados as disciplinas clássicas. Mesmo que esses autores defendessem uma abordagem indutiva de ensino e o trabalho laboratorial, no início do século XX observava-se que o livrotexto era o principal suporte para o ensino de ciências (BAPTISTA, 2010).

As discussões acerca da importância do Ensino por Investigação foram retomadas na década de 1950, momento este, em que se difundiu, nos Estados Unidos, um sentimento de perda da vanguarda tecnológica em decorrência do sucesso soviético ao lançar o Sputnik. Hurd (1958) enfatiza que esse acontecimento fez com que se passasse a questionar se o ensino de ciências ministrado nas instituições de ensino era condizente com o contexto econômico e tecnológico do período. Com o intuito de desenvolver a Alfabetização Científica nos estudantes, foram introduzidas no contexto escolar, atividades como as Feiras de Ciência, Clubes de Ciência e os protocolos experimentais (SANTOS, 2011). Isso fez com que se passasse a dar mais ênfase às atividades de investigação, pois entendia-se que elas possibilitariam aos estudantes a compreensão da natureza da ciência e a aquisição do método científico.

No contexto brasileiro autores que abordam o Ensino por Investigação (DEMO, 1996; MORAES, GALIAZZI, RAMOS, 2012) procuram se afastar do viés pragmático da pedagogia progressista, aproximando-se de uma perspectiva construtivista que parte da acepção que "o conhecimento que um indivíduo adquire não é simplesmente uma interiorização do meio, nem é apenas resultado do desenvolvimento de disposições inatas do sujeito" (MORAES, 2003, p. 109). Nessa perspectiva teórica, a investigação é entendida como uma prática que, por permitir a formulação de hipóteses, a exploração, 
a manipulação de materiais e a interação com os pares e com o meio favorece a aprendizagem das crianças.

Todavia, quando se analisa as práticas pedagógicas de professores da Educação Básica depara-se com um paradoxo. Se por um lado existe na literatura especializada, uma série de estudos que apontam o Ensino por Investigação como uma estratégia para o desenvolvimento da cidadania, da argumentatividade e da aprendizagem significativa, por outro, as práticas de investigação parecem ser restritas a contextos isolados. Uma das explicações pode estar relacionada ao fato de que o desenvolvimento de práticas de investigação requerem a modificação de referenciais epistemológicos, que, muitas vezes, permanecem implícitos nas práticas docentes (LORENZON et al, 2015). Contudo, ao adotar somente essa pressuposição corre-se o risco de produzir um discurso de responsabilização dos docentes por estes não realizarem atividades investigativas.

Por sua vez, Praia (2011) oferece importante subsídio para complementar essa pressuposição. Para o autor, a abordagem tradicional de currículo está assentada em uma lógica autocoerente, na qual objetivos, métodos de trabalho e avaliação convergem para as mesmas finalidades. Nesse viés, a introdução de uma abordagem investigativa no currículo requer uma alteração da lógica até então hegemônica, fazendo com que confiabilidade dada as provas e exames, concebidos como instrumentos de avaliação dos estudantes seja relativizada. Dadas as especificidades das práticas de investigação, torna-se necessário pensar em instrumentos avaliativos que enfatizem o processo de construção do conhecimento, servindo assim, como um recurso que dê visibilidade aos itinerários formativos e permitam aos estudantes a autorregulação de sua aprendizagem.

Diante disso, pensa-se que a documentação pedagógica, concebida como um princípio do Planejamento na Abordagem Emergente (SILVA, 2011), oferece importantes subsídios para pensar instrumentos avaliativos que podem ser empregados em uma proposta de Ensino por Investigação. Entende-se a documentação pedagógica como “[...] um procedimento usado para tornar a aprendizagem visível para que ela possa ser relembrada, revisitada, reconstruída e reinterpretada como base para a tomada de decisões" (FYFE, 2016, p. 274). Assim, documentar consiste em elaborar um conjunto de registros e reflexões sistematizadas sobre os acontecimentos cotidianos e 
que tem como finalidade comunicar ao docente os interesses e as necessidades das crianças, bem como dar visibilidade as suas aprendizagens (RINALDI, 2012).

Os docentes que optam por documentar a aprendizagem de seus alunos valem-se de múltiplos instrumentos de produção de dados, tais como filmagens de situações significativas, narrativas, descrições, escritas reflexivas e portfólios de aprendizagem. Neste artigo, enfatizar-se-á este último recurso, que é compreendido como "[...] uma coleção de itens que releva, conforme o tempo passa, os diferentes aspectos do crescimento e do desenvolvimento de cada criança" (SHORES, GRACE, 2001, p. 43). Logo, o objetivo deste trabalho foi investigar quais as contribuições do uso do Portfólio como instrumento avaliativo em uma proposta de Ensino por Investigação

O artigo está organizado em três seções. Na primeira, apresenta-se de modo mais detalhado os conceitos de documentação pedagógica e portfólios de aprendizagem, relacionando-os com a avaliação. Para tanto utilizam-se ideias de autores que tratam dos processos avaliativos na Educação Infantil (SILVA, 2011; MALAGUZZI, 2016; FYFE, 2016; RINALDI, 2012, 2016). Na seção "Procedimentos Metodológicos" apresenta-se o contexto em que foi realizado o estudo, os instrumentos utilizados para a produção do corpus e a técnica de análise de dados. Na terceira seção do estudo, analisam-se os dados produzidos. Por fim, disserta-se sobre a necessidade da avaliação ser um instrumento que comunique o docente a necessidade de readequar o seu planejamento pedagógico fazendo com que ele seja condizente com as especificidades da turma.

\section{PORTFÓLIO COMO INSTRUMENTO AVALIATIVO}

Na seção introdutória deste estudo, apresentou-se uma breve retomada da história das propostas de Ensino por Investigação, evidenciando que a sua origem histórica data do século XIX, mas que se consolida no século posterior, principalmente, a partir dos estudos pragmáticos de Dewey (1978) e do construtivismo social piagetiano (MORAES, 2003). Na literatura que aborda o Ensino de Ciências, a investigação é apresentada como uma abordagem de trabalho que permite aos estudantes conhecer termos e conceitos científicos, a natureza/epistemologia da Ciência e compreender a 
relação entre Ciência, Tecnologia e Sociedade. Além disso, Bayardo (2003) entende que o envolvimento em projetos de investigação fomenta o desenvolvimento de habilidades que podem ser agrupadas em sete núcleos que abrangem, respectivamente, habilidades de percepção, instrumentais, de pensamento, de construção metodológica, de construção social do conhecimento e metacognição.

Logo, pode-se afirmar que o Ensino por Investigação visa o desenvolvimento de um sujeito bio-psico-social, isto é, parte do pressuposto que as dimensões cognitivas não podem ser dissociadas de aspectos afetivos e culturais (MORIN, 2003). Tal pressuposição produz implicações diretas nos instrumentos que são empregados para avaliar a aprendizagem das crianças, visto que comumente estes visam mensurar competências intelectuais. Essa ênfase na cognição pode ser justificada quando se reconhece que a instituição escolar é decorrente de um projeto de mundo moderno que esteve assentado nos cânones racionalistas. As práticas pedagógicas de avaliação visavam a produção de um conhecimento objetivo, relativizando e minimizando a importância dos aspectos subjetivos no desenvolvimento da aprendizagem (LORENZON, SILVA, 2017).

Em uma perspectiva contemporânea, é uma condição ética romper com a pressuposição moderna de que a avaliação seria “[...] uma tecnologia necessária para as práticas de divisão, classificação e alocação e, sendo assim, um meio para impor a ordem e o exercício disciplinar" (DAHLBERG, MOSS, PENCE, 2003, p. 121). A partir disso, pensa-se que a avaliação pode ser compreendida como uma atitude de abertura e sensibilidade ao outro. Essa compreensão de avaliação assenta-se sobretudo no pensamento de Lévinas (2012), para quem "o Outro" não pode ser dominado de forma objetiva, mas sim como alguém que, em sua absoluta alteridade, tensiona a organização pedagógica e instiga a nossa própria existência como ser pensante.

Entende-se que essas reflexões em torno da avaliação precisam ser contempladas em uma proposta de Ensino por Investigação, uma vez que ambas convergem ao pressupor que o outro - a criança - é um indivíduo pleno e capaz, que não se encontra em um estado de minoridade. Nesse viés, evidencia-se que os recursos empregados para avaliar a aprendizagem infantil, dentro de uma lógica moderna, em que o ensino é marcado pela treino e instrução, tornam-se incoerentes, visto que propõem a 
mensuração de aspectos cognitivos e por visarem identificar o estado no qual a criança se encontra, não documentam os itinerários formativos pelos quais ela passou.

Autores, como Dahlberg, Moss e Pence (2003) e Rinaldi (2012), partem do pressuposto de que a documentação pedagógica é uma estratégia de avaliação adequada as propostas de ensino que se fundamentam em uma abordagem de protagonismo infantil. A documentação pedagógica, quando compreendida como um princípio do Planejamento na Abordagem Emergente (SILVA, 2011), contempla três ações: a escuta sensível, o registro e a reflexão.

A escuta sensível é entendida aqui no sentido que Rinaldi (2016, p. 236) atribui, ou seja, "um verbo ativo que envolve dar uma interpretação, um sentido à mensagem, e valorizar aqueles que são escutados pelos outros”. A escuta sensível, quando compreendida como a primeira etapa da documentação pedagógica, consiste em um ato de abertura a alteridade radical do outro, na qual o sujeito que escuta isenta-se de emitir qualquer juízo de valor sobre as situações que observa. Antes sim, coloca em suspeição a lógica predominante de atribuir determinadas atitudes a uma ação transgressora.

Os episódios registrados e as perguntas emergentes da escuta sensível passam a ser registradas de modo sistemático e organizadas (KINNEY; WHARTON, 2009). Rinaldi (2016, p. 120) afirma que a composição desse conjunto de informações pode ser elaborada por meio do "uso de instrumentos verbais, gráficos e documentários, assim como das tecnologias audiovisuais". Logo, percebe-se que escuta sensível e registro sistemático não podem ser compreendidos como momentos distintos ou etapas sucessivas, mas sim como acontecimentos concomitantes. O docente que reconhece a importância da documentação pedagógica para o desenvolvimento das suas práticas busca estar sempre munido de instrumentos que possibilitem a ela capturar momentos pertinentes e significativos para a análise.

Tendo constituído um corpus de documentos e registros, Mendonça (2009, p. 61) destaca que se inicia um movimento de "analisar e refletir, compartilhar interpretações para compreender o presente e projetar o futuro do trabalho educativo". A reflexão é inerente a documentação pedagógica, e por meio dela se possibilita que o docente supere a lógica da transgressão sob a qual, muitas vezes, subjuga-se o 
comportamento dos estudantes. Além disso, Malaguzzi (2016) afirma que foi este recurso que permitiu aos professores italianos tornarem-se autores de um saber da ação pedagógica que supriu lacunas existentes nos sistemas teóricos empregados para dar sustento teórico as práticas docentes.

Assim, pode-se definir a documentação pedagógica como um conjunto de registros sistematicamente organizados e analisados pelo docente e que permite a ele produzir sentido às situações que observa no seu cotidiano. Por ser um instrumento de avaliação flexível, há possibilidade de documentar as nuances subjetivas que ocorrem cotidianamente, sem reduzí-las a uma nota ou conceito. Com o intuito de torná-la adequada a uma proposta de Ensino por Investigação, pensa-se que a documentação pedagógica deve contemplar também uma avaliação dos estudantes sobre os seus próprios processos de aprendizagem.

Nesse viés, parte-se do pressuposto que os Portfólios de Aprendizagem Individual podem ser compreendidos como uma parte da documentação pedagógica. Define-se portfólio como " [...] coleção de itens que revela, conforme o tempo passa, os diferentes aspectos do crescimento e do desenvolvimento de cada criança" (SHORES; GRACE, 2001, p. 21). Mesmo que essas autoras entendam que cabe ao docente organizar os portfólios dos alunos, entende-se que cada criança pode ser autora de seu portfólio, tornando-se assim, responsável por selecionar produções, registros fotográficos ou descrições diárias que julga serem pertinentes para suas atividades.

Ao buscar encontrar instrumentos de avaliação que rompam com a abordagem classificatória e excludente, Pessate (2003, p. 23) entende que os portfólios correspondem a essa expectativa, visto que por meio deles é possível "conseguir mobilizar o estudante para a responsabilidade pessoal sobre seu processo de aprendizagem, favorecendo a análise de singularidades e peculiaridades do desenvolvimento de cada um". Ao narrarem suas próprias aprendizagens, possibilita-se às crianças que desenvolvam uma capacidade reflexiva e habilidades de ordem metacognitiva.

\section{PROCEDIMENTOS METODOLÓGICOS}


Este estudo caracteriza-se como uma pesquisa-ação, entendida aqui como um "método usado na pesquisa qualitativa, normalmente por professores, para registrar suas próprias observações com exatidão, enquanto revelam os significados que seus sujeitos trazem para suas experiências de vida" (GANDINI, 2012, p. 218). Na perspectiva apresentada, a pesquisa-ação é uma prática empregada por educadores e tem como objetivos principais ser uma estratégia de desenvolvimento profissional, produzir um saber da ação pedagógica (GAUTHIER et al, 2013) e ser um instrumento que fomente a resolução de problemas emergentes da própria prática.

O estudo foi desenvolvido com um grupo de 24 crianças o $3 .^{\circ}$ Ano de uma Escola Municipal de Ensino Fundamental localizada em um município do Vale do Taquari/RS, na qual o autor é docente. Com esse grupo de crianças emprega-se, usualmente, atividades de investigação com diferentes graus de abertura . Neste estudo, analisa-se as atividades de cunho investigativo que foram desenvolvidas em dois projetos distintos. $\mathrm{O}$ primeiro deles, denominado "A História do Sistema Monetário", foi desenvolvido nos meses de maio e junho de 2017 e teve como principal objetivo permitir que as crianças conhecessem diferentes objetos já utilizados por eles como moedas, bem como conhecer o dinheiro em vigor no país ${ }^{2}$. Por sua vez, o projeto "Conhecendo o Laboratório da Escola" consistiu em uma sequência de situações de aprendizagem que tiveram como objetivo explorar o Laboratório de Ciências da escola ${ }^{3}$.

No decorrer destes projetos, as crianças, diariamente, registraram em seus Portfólios de Aprendizagem uma avaliação das atividades realizadas, listaram as principais dificuldades no dia e descreveram o que aprenderam. Além disso, foi permitido que anexassem a ele objetos, textos, imagens e reflexões que julgassem

\footnotetext{
${ }^{2}$ No projeto sobre o sistema monetário, as crianças formularam questões sobre o que desejavam aprender e posteriormente elaboraram hipóteses para tais questionamentos. Posteriormente a isto, iniciou-se uma atividade de pesquisa de campo, no qual as crianças buscaram conversar com pessoas da comunidade escolar sobre suas dúvidas, trazerem para a escola coleções de moedas e cédulas, realizaram a busca de informações em textos e em meio digital e construíram réplicas de moedas antigas. Por fim, os dados encontrados foram sistematizados e apresentados em forma de uma breve exposição.

${ }^{3} \mathrm{O}$ projeto de familiarização com o Laboratório da Escola consistiu em uma sequência de atividades de caráter prático/experimental que abordavam, de modo simples, conceitos como densidade, produção de gás carbônico e atividades com imãs.
} 
pertinentes ao estudo realizado. Os Portfólios de Aprendizagem mantidos pelas crianças tornaram-se o principal instrumento para a produção do corpus da pesquisa. Todavia, com o intuito de complementar esses materiais, analisou-se também o Diário de Aula mantido pelo docente-pesquisador, sendo que neste foram registrados textos descritivos de situações que se julgou pertinente e os registros reflexivos sobre as práticas pedagógicas desenvolvidas.

Os dados produzidos foram analisados através de Análise Textual Discursiva que, conforme Moraes e Galiazzi (2011) correspondem a um procedimento de análise que permite ao pesquisador produzir significado a partir das significantes existentes em um dado material de análise. Para que isso aconteça, o analista precisa realizar um empreendimento de produção de unidades de significado (unitarização) para, posteriormente, reorganizá-las em categorias. Por fim, se produz um metatexto em que se descreve as novas compreensões obtidas.

\section{ANÁLISE DOS DADOS}

Nesta seção do estudo, propõe-se uma análise do corpus da pesquisa, buscando responder ao questionamento deste estudo sobre as contribuições do uso dos Portfólios como instrumento avaliativo em uma proposta de Ensino por Investigação. Os dados foram dispostos em três categorias que abordam, respectivamente, os Portfólios de Aprendizagem como instrumento que garante a visibilidade para os itinerários de formação, os Portfólios como recurso que possibilita a comunicação discente-docente e a relação existente entre a construção de Portfólio e o desenvolvimento de habilidades metacognitivas.

Muitas habilidades desenvolvidas por meio da Espiral Investigativa (LORENZON, 2018) não podem ser mensuradas pelos instrumentos, comumente, empregados. Ao retomar os núcleos de habilidades propostas por Bayardo (2003) e desenvolvidos em uma investigação, é possível perceber que avaliar e mensurar com precisão e objetividade, habilidades como a sensibilidade aos fenômenos, a intuição, a criticidade, a reflexividade e a autonomia intelectual é um procedimento complexo. A 
ausência de instrumentos objetivos faz que as abordagens investigativas sejam colocadas em suspeição, pelo fato de, aparentemente, não ensinarem nada às crianças.

Pagni (2014), no contexto da Educação Infantil, acredita que essas marcas podem ser evidenciadas por meio de instrumentos de documentação. Essa suposição ganha respaldo no pensamento de Kinney e Wharton (2009), quando afirmam que os registros produzidos pelas crianças são uma excelente oportunidade de compreendermos o modo pelo qual elas conhecem o mundo. Neste sentido, nas primeiras práticas experimentais que as crianças desenvolveram no Laboratório de Ciências da escola, quando questionadas sobre suas aprendizagens, enfatizavam que não haviam aprendido nada, pois apenas tinham realizado algumas experiências. Assim, a análise dos dados infere que para as crianças esse espaço da escola era um local recreativo e não um espaço de aprendizagem. Com base nisso, começou-se a solicitar que as crianças produzissem em seus portfólios desenhos das atividades e pequenas descrições.

No Portfólio da Criança Mi. (05 de maio) encontrou-se um registro de caráter mais descritivo "A gente viu diamantes. O professor deu uma pedra de carvão mineral e uma que se chama calcita e uma outra com algumas ametistas. Eu aprendi, que se tem cristais a pedra é de origem vulcânica. A outra pedra de origem vulcânica parecia um ninho de abelha". No caso deste relato, o estudante fez comparações para explicar a compreensão que teve do tema que estava sendo estudado. É importante destacar que a generalização de que as pedras de origem vulcânica possuem cristais, foi feita pela própria criança ao observar amostras de basalto e de granito que haviam sido disponibilizadas.

No dia 12 de maio, o grupo de crianças retornou para o laboratório com o intuito de realizar experiências relacionadas às reações químicas. A Criança Fe. registrou em seu portfólio que, "eu achava que reações químicas eram coisas que davam explosões". $\mathrm{Na}$ sequência de sua descrição, a criança optou por uma linguagem mais descritiva no relato do experimento realizado quando diz "Bicarbonato mistura com vinagre. $O$ bicarbonato mistura com o vinagre e ele vira gás carbônico, que é tóxico".

Nesse sentido, é possível afirmar que o uso de portfólios, primeiramente, auxiliou o docente a dar legitimidade a uma proposta de Ensino por Investigação, pois podem estar documentados as aprendizagens das crianças. Reconhece-se ainda que a 
análise dos registros fomenta um processo que nos permite identificar "modos como as crianças extraem sentido do seu mundo" (KINNEY; WHARTON; 2009, p. 23).

Destaca-se ainda que no ensino de ciências, um dos resultados esperados é garantir às crianças que desenvolvam a aprendizagem conceitual o que, muitas vezes, se torna um desafio ao docente. Assim, os portfólios dos alunos e as descrições presentes servem como indicador para que o professor conheça as definições conceituais produzidas pelas crianças. Ao retomar o registro da Criança Mi. percebe-se que ela designou como diamante qualquer pedra lúcida, sem reconhecer que manipulou pedras semi preciosas. No caso da Criança Fe. seu registro indicou que ela compreendeu que uma reação química não é um acontecimento mágico, mas sim decorrente de uma mistura de diferentes materiais.

Em relação ao Diário de Aula mantido pelo docente, há um relato no caso da criança Re. que apresentava dificuldades em seu rendimento escolar:

\begin{abstract}
A Criança Re. vem apresentando muitas dificuldades em todas as atividades que são propostas a ele. Em nossa conversa particular ele disse que "Eu sei, eu sou 'burro', só sirvo para desenhar. Eu sei disso”. Com base nessa afirmação, montei com ele um painel na sala para que ele expusesse seus trabalhos. Na área de matemática, diminui a quantidade de atividades para ele, mas pedi que após cada uma escrevesse quais as ações que ele fazia para resolvê-las, o que permitiu que percebesse onde ocorriam seus erros no momento de multiplicar. Os resultados aos poucos começaram tornar-se visíveis. Em seu Diário as escritas tornaram-se mais longas e narravam situações familiares, começou a usar o tempo de intervalo para ler na biblioteca, optou por começar escrever com letra cursiva e nas aulas de Ciência começou a levar materiais para analisar no Laboratório (casulos e flores) e pediu se eu o auxiliaria construir uma coleção de rochas que agora encontra-se exposta na sala (Diário de Aula).
\end{abstract}

Entende-se que neste caso, a criança, ao produzir seu portfólio começou a realizar um exercício autorreflexivo sobre suas próprias aprendizagens (KINEY, WARTON, 2009), o que, primeiramente, fez com que ele - e o docente compreendessem suas dificuldades e começassem a resolvê-las. Em um segundo momento, a percepção de que ele já havia avançado em alguns aspectos que apresentou dificuldades, serviu como motivador o desenvolvimento de novas habilidades cognitivas. 
A segunda categoria refere-se a pertinência dos Portfólios como um instrumento ${ }^{4}$ que permita uma comunicação efetiva entre docentes e discentes. Quanto à comunicação efetiva, entende-se que as crianças, em seu cotidiano, não empregam somente a linguagem oral para comunicar seus interesses e as suas necessidades, mas emprega múltiplas formas (SILVA, 2011). No caso dos portfólios, em decorrência das crianças terem oportunidade de utilizá-los também como um bloco de anotações nos quais registraram seus insights, foi possível encontrar uma série de questionamentos. A Criança Ma. (16 de maio), ao estudar o sistema monetário, realizou os seguintes registros em seu Portfólio: "Se eles tinham sementes com dinheiro, como eles tiveram a ideia de fazer notas e moedas?" e "Em que época eles criaram a primeira cédula?". Por sua vez, no dia 22 de maio, a Criança Re. destacou que queria saber " $O$ que são cheques?".

Esses questionamentos propostos pelas crianças são temas que são do seu interesse. Na proposta pedagógica de Dewey (1978), os interesses são compreendidos como algo propulsivo e ativo, isto é, um estímulo que nos envolve em determinadas tarefas. Silva (2011), ao comentar o pensamento do autor e suas implicações para o planejamento docente, afirma que contemplar os interesses das crianças no planejamento pedagógico permite aos docentes elaborarem situações de aprendizagem significativas aos envolvidos. Quando se fala nos portfólios como um instrumento de comunicação, entende-se que ele oferece ao professor pistas do que pode ser modificado em sua própria prática pedagógica, com o intuito de produzir situações de aprendizagem mais significativas aos envolvidos.

Ao prosseguir na análise do material produzido, percebe-se que, com o passar do tempo, as crianças atribuíram um papel de diário aos seus portfólios e registraram nele temas que julgaram pertinentes de serem estudados "Eu quero saber sobre os números romanos" (Criança La.), “Eu quero saber a lei (multiplicação) do 9” (Criança Ed.), “Eu quero saber Contas de divisão" (Criança Na.) e "Do que as salsichas são feitas de verdade?" (Criança Re.). Ao ler esses registros das crianças, torna-se possível conhecer um pouco mais sobre os interesses que elas possuem e também as suas necessidades.

\footnotetext{
${ }^{4}$ Os dados apresentados nesta categoria se referem ao projeto desenvolvido sobre o sistema monetário. Possivelmente, pelo fato da natureza das atividades desenvolvidas no laboratório escolar serem de caráter mais experimental, não houve identificação de dados que se referiam a comunicação entre discente e docente.
} 
Por fim, a terceira categoria tratou da relação existente entre os Portfólios de Aprendizagem e o desenvolvimento de habilidades metacognitivas e de autorregulação acadêmica, sendo a metacognição entendida como uma “[...] atitude reflexiva pela qual o aluno toma consciência dos próprios processos mentais" (GRILLO, FREITAS, 2010, p. 45). Nesse viés, destaca-se que a turma investigada apresentou dificuldades na organização e no desenvolvimento de trabalhos em grupos, o que fez com que se empregasse os Portfólios como um instrumento de autorregulação da aprendizagem. Assim, uma das atividades propostas no estudo do sistema monetário consistiu em organizar-se em grupos, pesquisar no Laboratório de Informática imagens de moedas primitivas e modelá-las em argila. Posteriormente, a esta tarefa, o docente solicitou às crianças que registrassem os seguintes dados em seus portfólios:
Escrever no seu Portfólio:
a) Quais os Materiais que você utilizou?
b) O que seu grupo havia planejado fazer?
c) Vocês conseguiram fazer o que planejaram?
d) O trabalho ficou como vocês esperavam?
e) Se você tivesse oportunidade de fazer novamente trabalho, o que você mudaria?
f) Como você se sentiu trabalhando no grupo? (Diário de Aula, 22 de fevereiro de 2017)

Nesta atividade, às crianças puderam optar por respondem as perguntas ou escrever um pequeno relatório da atividade. A Criança Da., que juntamente com o seu grupo confeccionou moedas chinesas, registrou: "nós iríamos utilizar argila, tampinha de garrafa, tesoura e as mãos. Nosso grupo planejou pegar as tampinhas, botar argila dentro e apertar. Depois tirar" (22 de maio de 2017). Por fim ela avalia que em sua atividade era necessário "Fazer a borda melhor na moeda". Nesse aspecto, os ganhos apresentados pelo uso do portfólio em projetos de investigação referem-se principalmente às possibilidades das crianças refletirem sobre as atividades que elas desenvolveram e avaliarem aspectos que precisaram ser melhorados.

Uma das dificuldades encontradas pelos docentes na realização de projetos de investigação, refere-se a pouco autonomia das crianças na realização dos seus trabalhos, o que faz com que o docente precise estar permanentemente ativo e dando orientações diretas às crianças. Pensa-se que quando há possibilidade de ampliar o envolvimento das crianças com suas atividades. 
Cabe destacar ainda, que como as crianças que participaram do estudo ainda se encontravam no ciclo de investigação, é possível que elas apresentassem dificuldades para formularem expressões que representem a avaliação do que pensam. Aqui, cito o exemplo da Criança Pa. quando afirma que "nós planejamos fazer uma moeda bonita. Não deu certo, porque não deu. Eu mudaria muitas coisas". Saliento que torna-se necessário permitir que as crianças pequenas empreguem a linguagem gráfica e os recursos audiovisuais para confeccionar seus portfólios.

\section{CONSIDERAÇÕES FINAIS}

No decorrer desta pesquisa, investiguei as contribuições do portfólio como instrumento avaliativo em uma proposta de Ensino por Investigação. A introdução de práticas investigativas no currículo escolar requer a alteração dos instrumentos de avaliação que comumente são utilizados, visto que estes, muitas vezes, se inserem em uma perspectiva de identificar se as crianças desenvolveram as habilidades esperadas e aprenderam os conteúdos estabelecidos pelo programa curricular. Por sua vez, em uma perspectiva de Ensino por Investigação, a avaliação deve fomentar o desenvolvimento do protagonismo infantil e da autonomia dos educandos.

Visto que, neste estudo ocupava o papel de pesquisador e docente da turma investigada, no decorrer das práticas investigadas, comecei a delimitar algumas estratégias de avaliação condizentes com as especificidades da proposta de Ensino por Investigação. A escolha e a aplicação dos portfólios foram decorrentes de uma aposta que esse instrumento poderia fomentar o desenvolvimento de habilidades metacognitivas e estimular as crianças a desenvolverem o controle volitivo de sua própria aprendizagem.

Os Portfólios são um importante recurso para criar um canal de comunicação entre a criança, o docente, a família e a sociedade, sendo que a análise das produções infantis permite que o docente reconheça temáticas que são pertinentes para serem inseridos no planejamento pedagógico. Corrobora-se com Shores e Grace (2001), quando afirmam que os portfólios são um recurso que dão suporte e fomentam as práticas pedagógicas centradas no protagonismo infantil. Entende-se que, no momento 
que os portfólios evidenciam os modos pelos quais as crianças aprendem, neles torna-se possível identificar pistas que indicam as origens das dificuldades que as crianças encontram para resolver determinadas atividades. Se isto for tomado como um insight pelo docente, este pode valer-se de estratégias de ensino que permitiriam um ganho real à criança.

Por fim, discutiu-se a relação existente entre o desenvolvimento da metacognição e o uso de portfólios de aprendizagens. O uso desse instrumento permite que a criança desenvolva um estado permanente de reflexão sobre as atividades que ela está envolvida e desenvolva um exercício de autoavaliação constante. No momento que a criança consegue desenvolver um conjunto de habilidades metacognitivas, entende-se que ela apresentará uma maior autonomia, pelo fato de conseguir identificar as etapas subsequentes que precisam ser desenvolvidas.

Com intuito de finalizar este estudo, destaca-se que tornou-se visível as possibilidades de empregar os portfólios de aprendizagem como instrumento que permite o monitoramento das aprendizagens infantis. Quando fala-se em monitorar, pressupõe-se que ao acompanhar o desenvolvimento da aprendizagem das crianças e investigar o modo pelo qual elas aprendem, o docente pode lançar mão de estratégias de ensino mais eficientes e condizentes com as especificidades dos estudantes. Os portfólios, na perspectiva apresentada, não possuem um fim em si mesmo ou são um meio para expressar um conceito sobre a criança, mas um suporte do qual o professor pode valer-se para auxiliar as crianças em seu processo de aprendizagem.

\section{REFERÊNCIAS}

BAPTISTA, M. L. M. Concepção e implementação de actividades de investigação: um estudo com professores de física e química do ensino básico. 2006. $561 \mathrm{fl}$. (Tese de Doutoramento). Doutoramento em Didáctica das Ciências.

BAYARDO, M. G. M. Desde cuándo y desde donde pesar la formación para la investigación. Educación y Ciencia - Nueva época. V. 7. N. 14 (28). Jul/dez 2003. p. 63-81. 
DAHLBERG, G. MOSS, P. PENCE, A. Qualidade na Educação da Primeira Infância: Perspectivas pós-modernas. Porto Alegre: Artmed, 2003.

DEMO, P. A pesquisa e construção de conhecimento: Metodologia científica no caminho de Habernas. - Rio de Janeiro: Tempo Brasileiro: 1996.

DEWEY, J. Vida e educação. 10. ed. São Paulo: Melhoramentos, 1978.

FYFE, B. A relação entre documentação e avaliação. In.: EDWARDS, C.; GANDINI, L.; FORMAN, G. (orgs.). As cem linguagens da criança: A experiência de Reggio Emilia em transformação. Porto Alegre: Artmed, 2016. p. 273-292.

GANDINI, L. et al. O papel do ateliê na Educação Infantil: Inspiração de Reggio Emilia. Porto Alegre: Penso, 2012.

GAUTHIER, C. et al. Por uma teoria da pedagogia: Pesquisas contemporâneas sobre o saber docente. 3 ed. Ijui: Ed. Unijui, 2013.

GRILLO, M. C.; FREITAS, A. L. S. de. Autoavaliação: por que e como realiza-las? GRILLO, M. C. et al (org). Por que falar ainda em avaliação? Porto Alegre: EDIPUCRS, 2010. p. 45-49.

HURD, P. D. Science Literacy: Its Meaning for American Schools. Educational Leadership, V. 16, 1958. p. 13-16.

KINNEY, L. WHARTON, P. Tornando Visível a aprendizagem das crianças. Porto Alegre: Artmed, 2009.

LÉVINAS, E. Humanismo do outro homem. 4. ed. Petrópolis: Vozes, 2012.

LORENZON, M. et al. Concepções epistemológicas que sustentam práticas de investigação desenvolvidas para e com crianças. In: TAUCHEN, G.; SILVA, J. A. da; SCHWANTES, L. (Org.). Educação Científica: Pesquisas e Experiências. 1ed.Curitiba: Editora CRV, 2015, p. 121-130.

SILVA, J. S. A disciplina no pensamento de Kant e Comenius: Influências na organização da escola moderna. Revista Vidya. v. 1. 2017.

A espiral investigativa como uma estratégia de desenvolvimento da Alfabetização Científica nos Anos Iniciais do Ensino Fundamental. Dissertação (Mestrado) - Universidade do Vale do Taquari - RS. Programa de Pós Graduação em Ensino, Lajeado - RS. 2018.

MALAGUZZI, L. Histórias, ideias e filosofias básicas. In.: EDWARDS, C.; GANDINI, L.; FORMAN, G. (org). As Cem Linguagens da criança: A Abordagem de Reggio Emilia na Educação da Primeira Infância. Porto Alegre: Penso, 2016. p. 57-98. 
MENDONÇA, C. N. de. A documentação pedagógica como processo de investigação e reflexão na educação infantil. 2009, 135 p. tese (Doutorado em Educação), Universidade Estadual Paulista “Júlio de Mesquita Filho”, Marília.

MORAES, R.; GALIAZZI, M. do C.; RAMOS, M. G. Pesquisa em sala de aula. In.: MORAES, R.; LIMA, V. M. do L. Pesquisa em sala de aula: tendências para educação em novos tempos. Porto Alegre: ediPUCRS, 2012. p. 11-20.

É possível ser construtivista no ensino de ciências? In.: MORAES, Roque (org). Construtivismo e ensino de ciências: reflexões epistemológicas e metodológicas. 2 ed. Porto Alegre: EDIPUCRS, 2003. p. 103-129.

Unijuí, 2011.

GAliAZZI, M. do C. Análise Textual Discursiva. 2. Ed. Ver. - Ijuí: Ed.

MORIN, E.. Os sete saberes necessários à educação do futuro. São Paulo: Cortez, 2003.

PAGNI, B. Olhar para o futuro através da memória: projetar, documentar e refletirs obre as experiências In.: FORTUNATTI, A. A abordagem de San Miniato para a Educação das Crianças: Protagonismo das crianças, participação das famílias e responsabilidade da comunidade por um currículo do possível. San Miniato: Edizioni CTS, 2014.

PESSATE, L. Portfólios como instrumentos de avaliação nos processos de ensinagem. In.: 26 Reunião Anual da ANPED - Novos governos. Novas Políticas? 2003, Poços de Caldas - MG. Anais da 26 ${ }^{\text {a }}$ Reunião Anual da ANPED - Novos governos. Novas Políticas?. Petrópolis - RJ: Vozes, 2003, p. 23-35.

PRAIA, J. F. Contributo para uma leitura possível de um percurso profissional. In.: CACHAPUZ, A. F.; CARVALHO, A. M. P.; GIL-PÉREZ, D. O ensino das ciências como compromisso científico e social: os caminhos que percorremos. São Paulo: Cortes Editora, 2011. p. 52-74.

RINALDI, C. A pedagogia da escuta: a perspectiva da escuta em Reggio Emilia. In.: EDWARDS, C.; GANDINI, L.; FORMAN, G. (orgs.). As cem linguagens da criança: A experiência de Reggio Emilia em transformação. Porto Alegre: Artmed, 2016. p. 235248. Terra, 2012.

Diálogos com Reggio Emilia: escutar, investigar e aprender. São Paulo: Paz e

SANTOS, W. L. P. dos. Significados da educação científica com enfoque CTS. In.: SANTOS, W. L. P. dos.; AULER, D. CTS e Educação Científica: desafios, tendências e resultados de pesquisas. Brasília: Editora Universidade de Brasília, 2011. p. 21-48. 
SHORES, E. GRACE, C. Manual de portfólio: um guia passo a passo para o professor. Porto Alegre: Artmed, 2001.

SILVA, J. S. da. O Planejamento no Enfoque Emergente: Uma experiência no $1^{\circ}$ Ano do Ensino Fundamentalde Nove Anos. Tese (doutorado) - Universidade Federal do Rio Grande do Sul, Faculdade de Educação, Programa de Pós-Graduação em Educação, Porto Alegre: 2011. 